\title{
APROXIMACION A LA EMPRESA ARIZU: ALGUNAS ESTRATEGIAS DE LA CONFORMACION E INCREMENTO DEL PATRIMONIO SOCIETARIO Y FAMILIAR 1884-1920
}

Ana María Mateu '

\section{Introducción}

Cuando la familia Arizu emigró hacia Argentina, nadie podía asegurarles el éxito de su diáspora. Seguramente en sus baúles traían los mismos petates que el resto de los inmigrantes. Sin embargo, ellos lograron no sólo "hacer la América", sino insertarse en el muy reducido grupo de bodegueros que llegaron a controlar la industria vitivinícola por espacio de varios años. El conjunto de factores que se los haría posible está plagado de mitos y constituye una madeja difícil de desenredar.

Dentro del marco del estudio de esta familia y de su actividad empresarial ${ }^{2}$, este trabajo tiene por objetivo analizar las estrategias desplegadas para la conformación de un patrimonio en tierras para la explotación vitivinícola en la Mendoza de principios de siglo, que llegó a ser conocido como "el paño de vides más grandes del mundo". Para esta investigación hemos tomado como unidades de análisis a los individuos, la familia y las redes extraparentales y comerciales a partir del análisis de la información de las fuentes empresariales y de los protocolos notariales desde 1884, año de la llegada del primer miembro de la familia, hasta 1920.

1 CRICYT-CONICET-Facultad de Ciencias Políticas y Sociales. UNCuyo.Mendoza.

E-mail: mateu@lanet.com.ar.

2 Este trabajo forma parte de una Tesis Doctoral sobre la Historia de la Empresa Arizu que aún no se encuentra finalizada, por lo que algunas de las conclusiones a las que hemos arribado pueden ser provisorias. 
La historia de empresas es una disciplina relativamente nueva en la Argentina ${ }^{3}$ y prácticamente inexplorada en Mendoza ${ }^{4}$, en donde los estudios sobre la economía vitivinícola no han puesto suficiente interés en la empresa como actor social, en la figura del empresario y su entorno familiar y en la formación de una "cultura empresarial" que ha desarrollado sus normas con el paso del tiempo. Las estructuras empresariales son significativamente históricas en esencia y solamente a través del análisis de casos concretos, se puede llegar a conocer en qué momento cambió el concepto de empresario y cuáles fueron las estrategias desplegadas a través del tiempo.

Creemos que la importancia de este estudio reside en que la escala microhistórica del enfoque nos brinda un nuevo marco de referencia para análisis más amplios sobre la economía vitivinícola y nos permite validar o reformular algunas de las versiones sobre el proceso de conformación de la alta burguesía vitivinícola y el papel en ella desempeñado por los inmigrantes. Por otra parte, nos permite conocer las estrategias que posibilitaron que los Arizu se ubicaran en periodo analizado en el tercer lugar dentro de los productores mendocinos, luego de las bodegas Tomba y Giol y Gargantini. Y por último nos acerca al conocimiento de la estructuración y el funcionamiento de las redes familiares, de paisanaje y clientelares como posibilitadoras y facilitadoras del éxito económico.

\section{En medio de una economía en expansión}

A fines de la década de 1870 y en estrecha relación con el ingreso del país al circuito capitalista internacional, se verificó en Mendoza un cambio en la estructura económica y el paso de un modo de producción basado en la ganadería comercial a otro centrado en la producción y transformación de la vid con fines comerciales. Luego de un momento de transición, ya sobre los años finales del siglo $\mathrm{XIX}$ y principios del XX encontramos en la provincia un sostenido proceso de desarrollo industrial.

La llegada del ferrocarril a Mendoza estuvo en relación directa con el cambio de estructura productiva, así como el arribo de inmigrantes que aportaron mano de obra y capital ${ }^{5}$. Dentro del nuevo modelo, un grupo minoritario y con una alta proporción de extranjeros (alrededor del $80 \%$ en 1895) tenía la propiedad de los medios de producción. La estructura productiva asemejaba una pirámide muy ancha en la base, ya que el $92 \%$ de las bodegas elaboraba menos de $10.000 \mathrm{hl}$ y solamente un $1 \%$ producía más de $40.000 \mathrm{hl}$, aproximadamente el $37 \%$ de la produc-

3 Para un análisis crítico sobre la historiografía sobre empresas en Argentina remitimos a Barbero, 1993.

4 Bragoni, 1999.

5 Mientras que en 1869 la población era de 65.413 habitantes, en 1895 alcanzaba a 116.136, y para el Centenario había llegado a 206.393. La proporción de extranjeros para las tres fechas era de 9,39\% (en su mayoría chilenos), $13,69 \%$ y $29 \%$ respectivarnente. Mientras que en 1869 la población era de 65.413 habitantes, en 1895 alcanzaba a 116.136, y para el Centenario había llegado a 206.393. La proporción de extranjeros para las tres fechas era de $9,39 \%$ (en su mayoría chilenos), 13,69\% y $29 \%$ respectivamente. 
ción. Este último es el grupo, conformado por no más de veinte personas, que hemos considerado miembros de la "burguesía vitivinícola", porque elaboraban más de $5.000 \mathrm{hl}$, y /o ocupaban posiciones destacadas en el aparato de estado, en los organismos crediticios o en las entidades sectoriales.

El crecimiento agrícola e industrial fue muy acelerado. En 1873 las hectáreas cultivadas de viña alcanzaban al 10,2\% de la superficie total de la provincia, mientras que en 1910 este porcentaje ascendió al 34,6\% y entre 1900 y 1915 se plantó un $98 \%$ más. El número de bodegas pasó de 334 en 1884 a 1398 en 1914 y su producción se incrementó un 90,4\% entre 1901 y 1915 . Entre 1884 y 1885 el vino pasó a ser nuestro primer producto de exportación para el mercado nacional, convirtiéndose en el tercer bien de consumo del país e insumiendo el 8,7\% del total de la canasta familiar. Ya a primera década del siglo XX, la provincia ocupaba el sexto lugar en el mundo y el primero en América del Sur en lo referido a la producción de vino, alcanzando para 1916 un volumen de $3.518 .000 \mathrm{hl}$, producido por 59.605 ha de viñedos.

La vitivinicultura se convirtió en la actividad económica hegemónica y llegó a representar en 1914 el $76 \%$ del PBI provincial, constituyendo las diez bodegas de mayor tamaño, el $15 \%$ de esa cifra. Los intereses representados por la industria vitivinícola adquirieron tanta importancia que llegaron a confundirse con los de la provincia, de la misma manera como se entremezclaron los intereses del estado y de la burguesía bodeguera .

Este proceso de consolidación de la economía vitivinícola, así como los intentos por solucionar sus primeros desajustes y conflictos, tuvieron en los Arizu, miembro destacado de lo que hemos definido como burguesía vitivinícola, a uno de sus principales protagonistas.

\section{Los hermanos Arizu}

A las oscuridades de la mayoría de las historias exitosas de inmigrantes, se les añaden las versiones contradictorias sobre la llegada a la Argentina de la propia familia Arizu. Dos hermanos, Balbino y Sotero, se disputaron el liderazgo dentro del ámbito de sus empresas y de la propia parentela. Sus descendientes, según la rama a la que pertenezcan, hacen recaer en uno u otro la responsabilidad de haber iniciado las actividades vitivinícolas en Mendoza ${ }^{7}$

Ambrosio y su prima Braulia Labiano tuvieron en Navarra siete hijos, el mayor de los cuales fue Balbino, nacido en 1858. La familia Arizu (que significa en vasco "robledal") se dedicaba a criar animales y a fabricar vino y aceite. En el pueblo natal, el invierno de 1880 fue muy crudo al igual que el de 1882. Las dificulta-

6 La política de protección del estado hacia los grandes bodegueros ha sido analizada en Mateu, 2002.

7 Fueron revisados más de 50 libros de Protocolos Notariales para ver si se encontraba cúal de los dos hermanos iniciaba las actividades. La primera documentación encontrada fue el otorgamiento de un poder en abril de 1887 por parte de Balbino a josé Gac para que lo represente y defienda en el juicio sobre liquidación de una sociedad que tuviera con Basterra. 
des económicas motivaron que Balbino fuera al pueblo cercano de Tafalla y allí conociera a Bernardino Izuel, un zaragozano que había traído de Argentina un lote de mulas para vender. Balbino se entusiasmó con viajar y a pesar de la resistencia familiar, llegó a Mendoza en 1883.

Primero trabajó en Rivadavia, en la construcción de un canal junto a su amigo Izuel y luego en la bodega de Don josé Corominas y en la de Tiburcio Benegas $^{8}$. Un tiempo después alquiló una viña, que trabajó con la ayuda de un peón y luego se unió con Ramón Basterra, otro vasco, para alquilar una bodega. El socio murió de cólera en la epidemia de 1886 y Balbino, quién no quedó en muy buena situación económica fue auxiliado por Tiburcio Benegas, su ex patrón, estableciendo de esta manera una sólida relación clientelar que le serviría de apoyo.

Cuando llegaron sus hermanos Clemente y Sotero (segundo y cuarto en la descendencia familiar) también trabajaron con Benegas y posiblemente con su ayuda lograron alquilar una bodega. Hay versiones coincidentes de que salieron con sus armas en defensa del gobernador durante la revolución de 1889 en la cual se lo intentó derrocar. Este gesto seguramente fue reconocido y recompensado por Benegas, impulsor además de la creación del Banco Provincia en 1888 y posiblemente el contacto con destacados personajes de la época que salieron como garantes en los préstamos contraídos por los Arizu con el Banco Provincia.

1889 fue también el año del casamiento de Balbino con Martina Basauri, una viuda con dinero, con la que no tuvo descendencia. El matrimonio se formalizó el 23 de febrero de 1889. Martina tenía 39 años y Balbino 30. De los datos de la sucesión de la esposa, que falleció el 23 de noviembre de 1914 se desprende que tenía bienes propios: una elegante casa en calle Las Heras y una finca de 4.080 metros cuadrados en Godoy Cruz, terreno inicial desde el que se expandió la bodega?.

En marzo de 1889 y seguramente en estrecha relación con este casamiento los hermanos organizaron la sociedad Balbino Arizu Hnos., cuyo capital inicial fue de $\$ 7.850$, aportados de la siguiente manera: Balbino $\$ 3.750$, Clemente $\$ 2.100$ y Sotero $\$ 2.005$. Ese año fue decisivo en la historia familiar. También fue el de la compra de los terrenos de Godoy Cruz para ampliar la bodega. Y por último 1889 fue el año del fallecimiento de Clemente, motivo por el cual Jacinto, el hermano menor, fue llamado para que viniera desde España y se incorporara a la sociedad familiar.

Otra es la historia que cuentan los descendientes de Sotero, en quien hacen recaer la responsabilidad de haber iniciado las actividades del grupo. Según ellos, fue el cuarto hermano en la línea familiar el primero en llegar a Mendoza trabajando como obrero del ferrocarril. Su partida de España había tenido que ver con su lugar en la descendencia y con una mala relación con Balbino. El único capital

8 Tiburcio Benegas, de origen rosarino, fue financista, gobernador (1886-1889), bodeguero y tuvo un destacado papel en la creación del Banco Provincia

9 Protocolos Notariales. AHM. Libro 1237. 23 de noviembre de 1914. 
que habría traído fue una moneda de oro, que parece que nunca quiso cambiar. Trabajó como carrero de Honorio Barraquero y llegó a tener su propia tropilla. Las noticias sobre las posibilidades de progreso económico que llegaban a través de las cartas a sus padres, fueron el desencadenante para que Balbino se trasladara a Mendoza y se asociara a su hermano. Sotero se casó con Balbina Villasante, de cuya unión nacieron seis hijos. Murió muy joven, a los 42 años, en 1912. Tuvo un papel decisivo en la trayectoria del grupo Arizu, opacado por la figura de Balbino, una especie de patriarca, que al no tener hijos propios se dedicó plenamente a la vida familiar. Por su parte, Jacinto se casó con Dámasa Zabalsa, con quien tuvo 7 hijos.

Los tres hermanos integraron la S.A. en 1908, pero además tenían sus propiedades particulares. Por su parte, Leoncio, hijo de un primo y nacido en España en 1883, vino a los 7 años a Mendoza a vivir con su tío Balbino. Desde su llegada se fue interiorizando de las actividades familiares y a partir de 1908, a los 25 años comenzó a trabajar de gerente en la S.A. hasta que en 1922 se dedicó a sus propios negocios, que adquirieron un volumen importante. Hoy sus descendientes producen, en la bodega que lleva su nombre, los afamados vinos Luigi Bosca.

Los Arizu se insertaron exitosamente en la sociedad mendocina. Ya en 1912 durante su visita a esta provincia el embajador español se alojó en la casa de Balbino, quien dos años después, fue condecorado por Alfonso XIII con el título de Caballero de la Real Orden de Isabel la Católica. Fue un gran propulsor del mutualismo de la colectividad española y los tres hermanos colaboraban en la Sociedad Española de Socorros Mutuos, en la Sociedad Española de Beneficencia, el Orfeón Español y el Hospital del Carmen.

Las actividades de Balbino fueron múltiples. Fue Director del Banco Mendoza, miembro de la Bolsa Vitivinícola en 1907, del Centro Vitivinícola Nacional y de la Cooperativa Vitivinícola, del Centro de Bodegueros y concejal por Godoy Cruz.

En 1926 murió Jacinto y Balbino en1936, el día de su cumpleaños número 78. La empresa quedó en manos de Sotero S., hijo de Sotero, casado con una prima hermana, con la que no tuvo descendencia y que al fallecer en 1955, fue sucedido por dos de sus primos, Ernesto y Ambrosio, hijos de Jacinto. A fines de los 70 el paquete accionario fue comprado por Héctor Greco, un oscuro y controvertido inversor que con su espectacular caída, arrastró a la ruina al emporio de los Arizu.

Pero, en los inicios, ¿qué fue lo primero? ¿La difícil situación europea, la tenacidad propia de los pueblos vascos a los que pertenecían los Arizu o la coyuntura económica mendocina? Las múltiples interrelaciones entre todos estos factores fueron tejiendo una trama que nos sirve de telón de fondo para el desarrollo de las actividades del grupo familiar Arizu.

\section{El entretejido y la operatividad de las redes sociales}

Los nuevos enfoques historiográficos sobre inmigración han puesto su én- 
fasis sobre las redes de relaciones sociales ${ }^{10}$ que operaban ya desde el momento en que se decidía la partida desde la Europa natal. Contar con un amigo o pariente que permitiera acrecentar las posibilidades de lograr "hacer la América" o amortiguar los efectos del desarraigo, del fracaso económico, de los accidentes de trabajo, de los problemas familiares.

En el caso de Balbino Arizu, fue Bernardino Izuel, un zaragozano a quien conoció en Tafalla, quien lo entusiasme contándole las posibilidades de inserción laboral en una provincia como la de Mendoza, que estaba en los inicios de un proceso de expansión de su economía. Este contacto será el estructurador de las oportunidades en las que debemos situar la personalidad y el afán de progreso de los hermanos. Esta red solidaria que se estructura en España no funcionará solamente como "red de arribo", sino que seguirá actuando durante muchos años y servirá de puente para otras nuevas fundadas en el paisanaje. Los vínculos tendrán un valor estratégico no sólo para el proceso de integración sino que explican el éxito económico del grupo. Serán el primer capital, el "capital relacional", con que cuente el grupo familiar y que no se agotará en los lazos parentales sino que se hará extensivo a otros miembros de la comunidad de origen español y en especial al vasco". La expansión de la empresa hacia el sur mendocino, tuvo, entre otras razones, como impulsor a Izuel, quien fue uno de los pioneros en la ocupación de las tierras del sur provincial y quien entusiasmó a los Arizu e incluso les vendió las primeras tierras.

Estas formas de reclutamiento regional y microregional se comprueban en las listas de empleados y hasta de los comerciantes de los vinos de la bodega. Las listas de trabajadores de las fincas y bodegas nos muestran una marcada preferencia hacia los españoles. Entre ellos, los mensuales, generalmente oriundos del mismo pueblo de España que los propietarios, tenían ciertos privilegios (leña, luz, vino y casa gratis, modestas pero cómodas), gozaban de estabilidad laboral y contaban con personal a su cargo integrando los "mandos medios" pero dedicaban muchas horas a la empresa.

Las redes de paisanaje también servían de estructuradoras de relaciones comerciales para la venta de los vinos de Arizu. El 44\% de los clientes que aparecen en los libros de Expendio de Vinos de la bodega tienen apellidos españoles y algunos demarcan claramente sus orígenes vascos, como por ejemplo, Egusquiza, Maiztegui, Ezquerra, Iñiguez, Ormaechea, Eizaguirre ${ }^{12}$.

La llegada de Balbino fue mediada por Izuel y a su vez Balbino medió en la de sus hermanos y sobrinos. Pero la figura del mediador con la nueva sociedad

10 Entendemos por red a las relaciones personales que un individuo configura en torno suyo y que pueden estar asentadas sobre lazos de vencindad, amistad, parentesco, o relaciones económicas o políticas. Para mayor información remitimos Bjerg y Otero, 1995.

11 En el imaginario colectivo los vascos eran considerados como un pueblo duro y resistente al trabajo rural. Ver para el caso de Rosario a Frid de Silverstein en Bjerg y Otero, 1995.

12 Mateu, 1998. 
podía abarcar un amplio espectro y generaba distintos tipos de relaciones. Los vínculos a veces eran recíprocos y a veces asimétricos, facilitando la presencia de relaciones patriarcales como las que ejercía don Balbino con sus empleados y con sus familiares.

\section{Las empresas familiares}

Los primeros pasos empresarios de Balbino estuvieron asentados sobre lazos de paisanaje. En 1887 inició sus "negocios de vino y bodega"13, bajo el nombre de "ARIZU y Cia." con Ramón Basterra. En el Libro Diario de $1887^{14}$ se registraron las operaciones de esta sociedad, que ya estaba dando utilidades y en la que Sote$\mathrm{ro}^{15}$ se encontraba empleado, aunque no en forma estable, recibiendo un salario según días trabajados ${ }^{16}$.

Creemos que estos momentos fundacionales sirvieron como experiencia piloto de la futura empresa familiar, debido a que muchas de las redes comerciales y laborales ${ }^{17}$ que se iniciaron en ese momento, se conservaron a lo largo de los más de treinta años analizados ${ }^{18}$. Desde sus inicios la sociedad comenzó a vender sus vinos a Ongay y Cia. en Rosario y a Manuel Irisarri en San Luis y mantenía relaciones comerciales ${ }^{19}$ con Domingo Tomba, con Honorio Barraquero y con la bodega Trapiche de Tiburcio Benegas, el ex patrón y fiador.

De los datos del Libro Borrador de $1888^{20}$ surgen indicios de que a la muerte de Basterra en una epidemia de cólera, Sotero cobró protagonismo en el manejo de la bodega y en la venta de damajuanas y bordalesas de vinos blancos y aguardientes. Durante ese periodo se registraron operaciones bancarias de descuento de documentos en el Banco Nacional, demostrando una temprana inserción comercial'21.

El casamiento de Balbino con Martina Basaurri lo colocó nuevamente en una situación de predominio, que de alguna manera y dentro de los límites culturales de la época, fue compartida por su mujer ${ }^{22}$. La concreción de este matrimonio, sin duda, estuvo en estrecha relación con la conformación de la primera sociedad

13 No hay mayor información sobre esta sociedad inicial que no está asentada en los Protocolos Notariales, salvo su pedido de disolución en 1888 , luego de la muerte de Basterra en la epidemia de cólera de 1886. Mendoza. Protocolos Notariales. AHM. Libro 426.fs.247. 1 de abril de 1887.

14 Arizu, Libro Diario de 1887.

15 Se desprende de los datos obtenidos que los hermanos comparten una casa, cuya manutención y alquiler es pagado por esta sociedad.

16 Se le liquidan 73 días de trabajo a $\$ 2$ por jornal.

17 Es interesante destacar que se registran pagos por papeletas de conchabo, lo que comprueba la coexistencia de formas coactivas con un mercado libre de trabajo.

18 Citamos a modo de ejemplo, los casos del tío y los primos Iracheta y de Irisarri, Zubieta e Izuel. Florencio Villasante, futuro suegro de Sotero, recibió durante 18888 y 1889 un pago por la manutención de éste. 19 Se registran cancelaciones de documentos con interés con estas importantes figuras de la vitivinicultura provincial.

20 Arizu, Libro Borrador, 1888.

21 Protocolos Notariales. AHM. Libro 426.fs.247.1 de abril de 1887

22 Son frecuentes los retiros de dinero realizados por la esposa de Balbino en forma personal. 
familiar y les hizo posible convertirse en accionistas del flamante Banco Provincia, de capital mixto.

En 1889 Balbino, Clemente (que murió ese año) y Sotero integraron la razón social "Balbino Arizu y Hnos.". Sus objetivos fueron la explotación de vinería, arriendos de viña y potreros y su duración fue por 3 años prorrogables. Del capital de $7850 \$, \$ 3.750$ habían sido aportados por Balbino, $\$ 2.100$ por Clemente y $\$ 2.005$ por Sotero. La gerencia fue desempeñada por Balbino, a quien le correspondió el $40 \%$ de las utilidades, mientras que a sus hermanos el $30 \%$ a cada uno ${ }^{23}$.

En 1904 se conformó una sociedad solidaria ${ }^{24}$, que conservó el nombre de la anterior y que incorporó a Jacinto, otro de los hermanos, en lugar del fallecido Clemente. Sus objetivos fueron la explotación vitivinícola en todas sus rubros. El capital fue notablemente superior: los $\$ 7.850$ de la primera sociedad familiar, cuyo pasivo y activo compraron, se aumentaron a $\$ 1.437 .068$ representados por propiedades, bodega, máquinas, vinos, dinero, créditos. De este capital correspondían a Balbino $\$ 630.000$, a Sotero $\$ 505.927$ y a Jacinto $\$ 301.104$. El reparto de las utilidades se haría en tres partes iguales, y la gerencia fue desempeñada por Jacinto, con un sueldo de $\$ 1.000$.

Esta sociedad familiar ${ }^{25}$ actuó en el mercado vitivinícola desde enero de 1905 hasta el 31 de diciembre de $1907^{26}$, cuando fue reemplazada por una sociedad anónima que a la vez que salvaguardaba una parte de los bienes personales de los hermanos, incorporaba capitales extrafamiliares. A los hermanos Arizu se les unió el sobrino Leoncio y Gaudencio Hugalde, Angel Martínez ${ }^{27}$ y Rafael, Manuel y Francisco Mercado y su apoderado Juan Narbondo. Los hermanos Mercado eran los principales compradores y distribuidores de los vinos Arizu en la Capital Federal y provincia de Buenos Aires y manejaban el $15 \%$ del total de las ventas de la bodega.

Asociar a los principales distribuidores de sus vinos, permitió a los Arizu suprimir intermediarios y visibilizar una parte importante del mercado interno, coordinando las funciones de funciones de producción y distribución de los flujos de productos. Mediante esta estrategia, no sólo se apropiaron de una importante y antigua clientela en la principal plaza consumidora sino que redujeron los costos de información sobre el mercado, asociando al riesgo empresarial a sus principales comerciantes. Luego de este paso intermedio, vendría el establecimiento de una planta distribuidora en Buenos Aires.

Los objetivos de la S.A., que duraría veinte años, seguían limitados a la explotación de los ramos de bodega, viñedos y similares relacionados con la vitivini-

23 Protocolos Notariales. AHM. Libro 452.Fs.278.15 de marzo de 1889.

24 Protocolos Notariales. AHM. Libro 726. 20 de febrero de 1904.

25 Entendemos por empresas familiares a aquellas cuya propiedad está en manos de una familia y en las que las relaciones de parentesco se extienden a propietarios y directivos

11427 Hugalde y Martínez eran dos abogados mendocinos. 
cultura. Su sede era Godoy Cruz, sin perjuicio de establecer sucursales en cualquier punto de la República ${ }^{28}$. Los hermanos Arizu aportaron a la nueva sociedad $\$ 1.135 .000$ representados por la bodega de Godoy Cruz con todos sus útiles y maquinarias y la finca del Carrizal, ambas de propiedad de la razón social Balbino Arizu Hnos. El capital social, íntegramente suscripto, era de $\$ 2.000 .000$ representado por 2.000 acciones nominales de igual valor y por series de igual número de acciones de 1.000. Las acciones de Balbino eran 461 y debería integrar hasta 605, las de Sotero 382, debiendo completar hasta 500 y Jacinto, quien poseía 292 debía llegar hasta las 383. Los socios minoritarios eran Leoncio con 6 acciones, Ugalde y Martínez con 3, cada uno, Narbondo con 120, Rafael Mercado con 370, Manuel Mercado con 5 y Francisco Mercado con 5. Para ser presidente o vice se necesitaba poseer como mínimo 100 acciones. El reparto de utilidades se haría de la siguiente manera: $2 \%$ para el presidente, $3 \%$ para los miembros del Directorio, $15 \%$ para el fondo de reserva y $80 \%$ para los accionistas.

En 1910 se modificaron los estatutos y se aumentó el capital social a \$ $10.000 .000 \mathrm{~m} / \mathrm{n}$ dividido en 100.000 acciones de $\$ 100$ cada una que fueron entregadas a la suscripción pública. En 1914, el síndico Angel Martínez fue reemplazado por una Consultora Internacional, "Price and Waterhouse", acorde con una empresa cuyos títulos habían llegado a la Bolsa de Londres ${ }^{29}$.

El protagonismo de Balbino fue indiscutible desde los inicios, hasta que 1915 renunció por motivos de salud y fue reemplazado por Rafael Mercado. La empresa había apostado por el sur mendocino y puesto en producción 13.375 ha durante 1912, a la par que había seguido comprando tierras, maquinarias y útiles y comenzado la construcción de la bodega en Villa Atuel.

Las fuertes inversiones, la crisis vitivinícola ${ }^{30}$, las repercusiones de la Primera Guerra Mundial y el alto nivel de endeudamiento con el Banco Nación" ${ }^{31}$, impactaron sobre el managment empresarial. Los problemas financieros llevaron a que en 1913 Mercado, intentara conseguir un empréstito por $\$ 1.500 .000$ oro $\mathrm{m} / \mathrm{n}$. en obligaciones hipotecarias, sin conseguirlo. Al año siguiente se solicitó un crédito al Banco Nación por $\$ 950.000 \mathrm{~m} / \mathrm{n}$ por el término de 6 meses, con el $8 \%$ de interés anual $^{32}$. Como garantía de la deuda se hipotecó una propiedad de Jacinto, ubicada en Luján, de 214 ha (200 de viñedos y 14 de potreros) ${ }^{33}$. En 1915 el Banco exigió un refuerzo de garantía y por ello se prendaron las acciones de la S.A por un valor nominal de 2.000.000. Se facultó al Banco para que en caso de que no fuera paga-

28 Los estatutos fueron aprobados por el Ejecutivo por decreto del 31/12/1907.

$29 \mathrm{El}$ Censo Nacional de 1914 menciona a esta firma entre aquellas que cotizaban en la Bolsa de Londres, pero no tenemos información en los libros de la empresa sobre este tema.

$30 \mathrm{El}$ precio del vino descendió desde \$20 por hl en 1912 a \$6 en 1915.

31 La empresa también era deudora del Banco Provincia, Londres, Español, del Anglo y del Alemán.

32 Protocolos Notariales. AHM. Libro 1209. Fs.1063. 7 de octubre de 1914.

33 Llama la atención que no fueran hipotecadas tierras de Balbino, lo cual puede hacernos suponer falta de confianza del Banco o problemas políticos, presumiblemente vinculados a su cercanía con Civit, que había caído en desgracia luego de su segundo gobierno. 
da la deuda, se vendieron o hicieran vender parte o todos los títulos prendados. Por otra parte, el Banco nombró a Gaspar Cornille para que formara parte del Directorio y de la Asamblea en representación solamente de 200.000 de los 2.000 .000 en acciones. Se le limitó el poder de acción de Balbino, ya que sin consentimiento escrito del Banco no podría representar el 1.800.000 de acciones restantes ${ }^{34}$.

La complicada situación por la que atravesó la empresa en ese año debió haber producido en Balbino un quiebre en su voluntad. Tenía 57 años y llevaba 32 luchando por su empresa. Sin embargo, Balbino se alejó solamente 5 años de la presidencia de la empresa, para volver a conducirla en 1920, cuando la deuda con el Banco Nación había sido saldada ${ }^{35}$.

La SA se manejó como una empresa familiar, aunque para mayor información sobre el manejo podrá ser conocida solamente a través de las Actas de las Asambleas a las que aún no hemos podido acceder. Los roles principales en la sociedad se mantuvieron en manos de la familia Arizu. Jacinto, el quinto hermano en la línea familiar y junto a Balbino, el único varón sobreviviente luego de la muerte de Sotero en 1912, se desempeñó como Secretario-Tesorero y como gerente de la empresa. Únicamente en 1910 se tomó la decisión de incorporar un gerente ajeno al grupo, Pedro Iribarne, que duró solamente un año en sus funciones y fue reemplazado por Jacinto, quien a su vez fue reemplazado en su cargo de Secretario Tesorero por Sotero. Jacinto luego volvió a mantener el cargo de Secretario Tesorero.

\section{La expansión agrícola de la familia Arizu y sus empresas}

En base a la información extraída de alrededor de casi 1.500 libros de Protocolos Notariales hemos podido conocer las operaciones inmobiliarias realizadas por las empresas familiares y por los Arizu en forma personal. De su análisis surgen las siguientes conclusiones:

\subsection{La empresa farniliar "Balbino Arizu y Hnos."}

La empresa familiar data de 1889 , pero las primeras compras de tierras las realizaron a partir de 1891, cuando se adquirieron $4000 \mathrm{~m}$ cuadrados en Godoy Cruz donde se construyó la Bodega, que se añadirán a los aportados por Martina Basaurri a su matrimonio con Balbino. La segunda operación fue la adquisición al Obispo de la Reta de una propiedad de 78 ha en Maipú, en la zona de Chachingo, zona muy apta para la vitivinicultura. La compraron a plazo y con garantía hipotecaria. Ambos inmuebles integraron el núcleo inicial con que se formó la S.A.

El gráfico № 1 que analiza la superficie total por año comprada por la empresa familiar marca 3 picos. El primero es el de 1894 ya analizado. El segundo se produce en 1902 por la compra de 1640 ha en Carrizal y por el aumento de la su-

34 Protocolos Notariales. AHM. Libro 1298. Fs. 862. 10 de setiembre de 1915.

35 En el período 1920-1928 no se registran deudas con el Banco Nación, aunque sí hay un fuerte endeudamiento con el Banco Anglo. 


\section{Gráfico1}

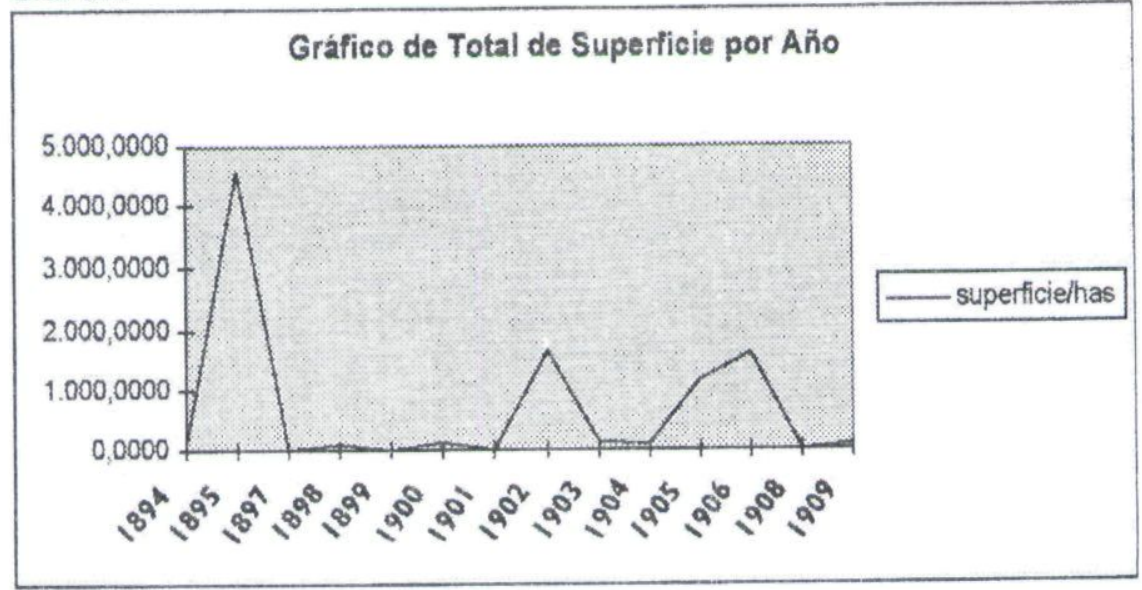

perficie destinada a la Bodega. Y por último el de 1905-1906 cuando se produjo la primera expansión al sur, hacia la zona de Villa Atuel en San Rafael a través de la compra de 2.520 ha de terreno cultivable a Bernardino Izuel, primer contacto de Balbino con Mendoza y el mediador para su inserción económica. Se pagó a razón de $\$ 100$ la hectárea, precio bajo dentro del mercado de tierras de la época y seguramente explicado por los lazos ya analizados con izuel.

La expansión hacia el sur se sustenta en la mayor facilidad para conseguir derechos de agua en una zona que recientemente había sido incorporada a la economía provincial. Luego del fin de la Campaña al Desierto, y unos años más tarde con la llegada de una importante cantidad de inmigrantes y de las vías del ferrocarril, el oasis sur de la provincia había atraído la atención de los inversores. Las tierras que eran compradas muy baratas se valorizaban rápidamente, más aún cuando se conseguía derecho de riego. El bajo precio relativo de las mismas fue realmente decisivo. En 1906, mientras que los Arizu habían invertido en Luján a razón de \$ 694 por ha, las compras en Atuel oscilaban entre los \$50 y \$100 por hectárea.

El Gráfico 2 que analiza las compras de tierras realizadas según el capital utilizado nos muestra los tres años en los que la Empresa realizó mayores inversiones. En 1900 se compraron 147 hectáreas en Luján a \$63.536, en 1903 se le añadieron 133 hectáreas por una suma de $\$ 64.000$ y en 1906 el aumento de inversiones estuvo señalado por la ya analizada expansión hacia el sur.

En este período la familia encaró una política de expansión y consolidación de su patrimonio. Se compró un total de 9.564 ha, de las que se vendieron solamente 76. 


\section{Gráfico 2}

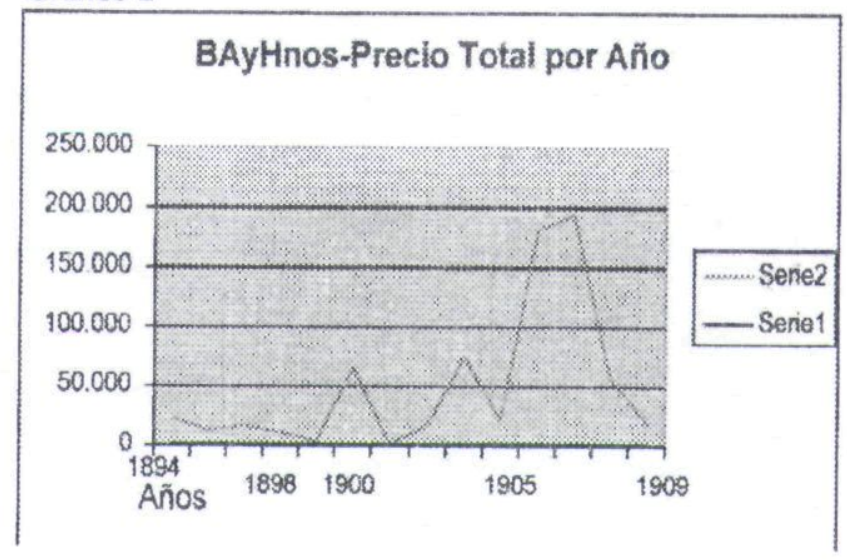

\subsection{Bodegas Arizu S.A.}

La S.A. en su evolución hasta 1920 tiene dos momentos de expansión muy marcados (Gráficos № 3 y 4). El primero corresponde al período de su conformación y el segundo al año 1911 en el que se compraron 264 hectáreas en Chachingo a $\$ 1.300 .000$ y a un valor por hectárea de $\$ 4.912$. También se adquirieron 49 hectáreas en Barrancas por un valor de $\$ 60.000$ a $\$ 2.091$ la hectárea y 3.626 hectáreas en Atuel, por un valor de $\$ 1.100 .000$ a un precio que oscilaba entre $\$ 250$ y \$669 por hectárea.

En el período analizado la S.A. solamente vendió 74 hectáreas por un valor de $\$ 100.000$.

Gráfico 3

\section{Sociedad Anónima Bodegas Arizu- Superficie Total por Año}

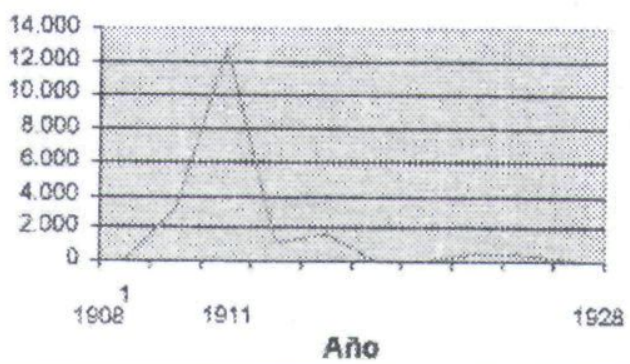




\section{Gráfico 4}

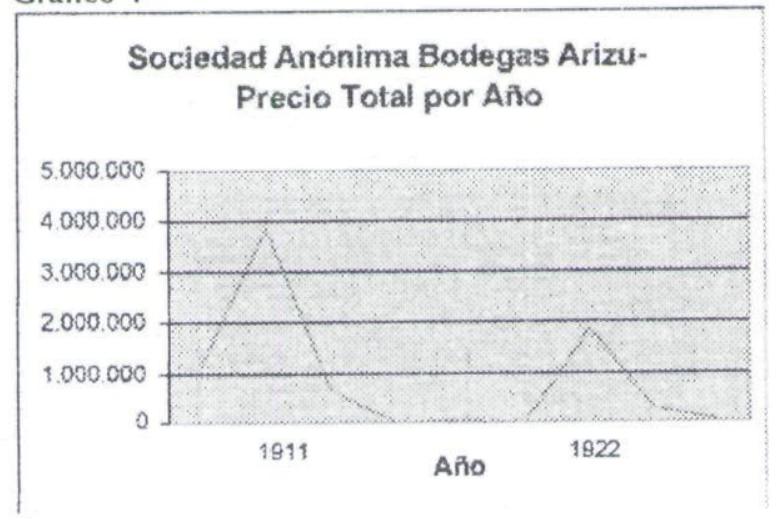

Es interesante analizar que en el momento de la conformación de la S.A, hay un reparto y traspaso de propiedades entre los hermanos. Como patrimonios personales y que no pertenecen a la S.A. Balbino se quedó en 1908 con 1.456 ha, Jacinto con 1703 y Sotero con 2.068 ha.

\subsection{Balbino Arizu}

Balbino realizó su mayor inversión en 1908 al comprar 900 hectáreas en San Rafael a $\$ 90.000$ y a un valor de $\$ 100$ la hectárea y 314 hectáreas en Maipú invirtiendo $\$ 514.686$ a valores por hectárea que van desde $\$ 2.198$ a $\$ 784$. En 1910 también hay una inversión importante por la compra de 229 hectáreas en Atuel y de 82 en Rodeo del Medio (Gráficos №5 y 6).

En el período analizado Balbino compró 1493 hectáreas por un valor de $\$ 675.315,65$ y se desprendió de 1491 por un valor de $\$ 2.057 .583$.

\section{Gráfico 5}

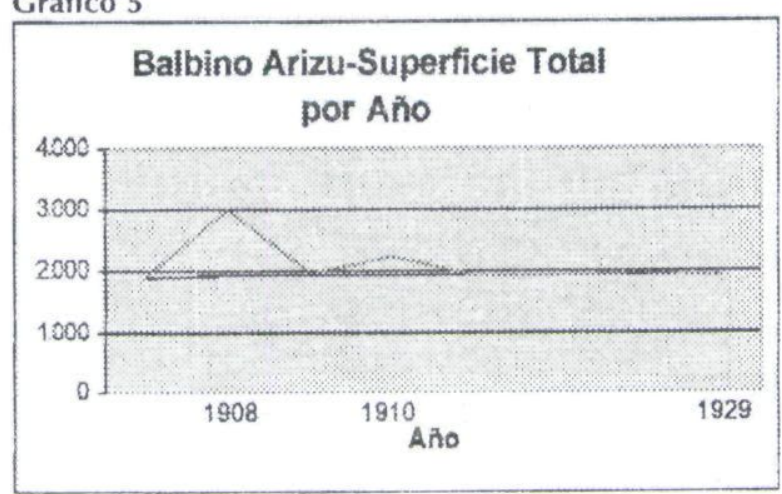




\section{Gráfico 6}

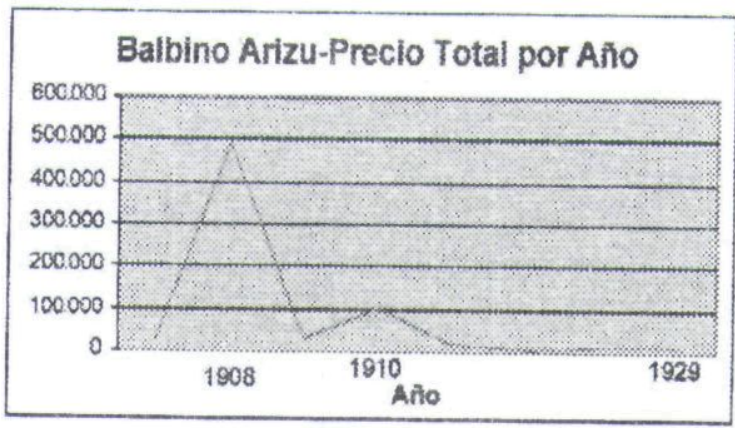

\subsection{Jacinto Arizu}

Jacinto fue el que más operaciones por fuera de la Sociedad realizó. En un total de 26 operaciones de compra y venta, llegó a acumular 1.843 hectáreas, invirtiendo \$364.237. La propiedad de mayor superficie fue adquirida en 1908 en Luján, bajo el nombre de "Villa Clara", al igual que 900 has en Atuel, bajo el nombre de "Bella". En 1910 compró 274 ha en San Rafael. (Gráficos 7 y 8)

Gráfico 7
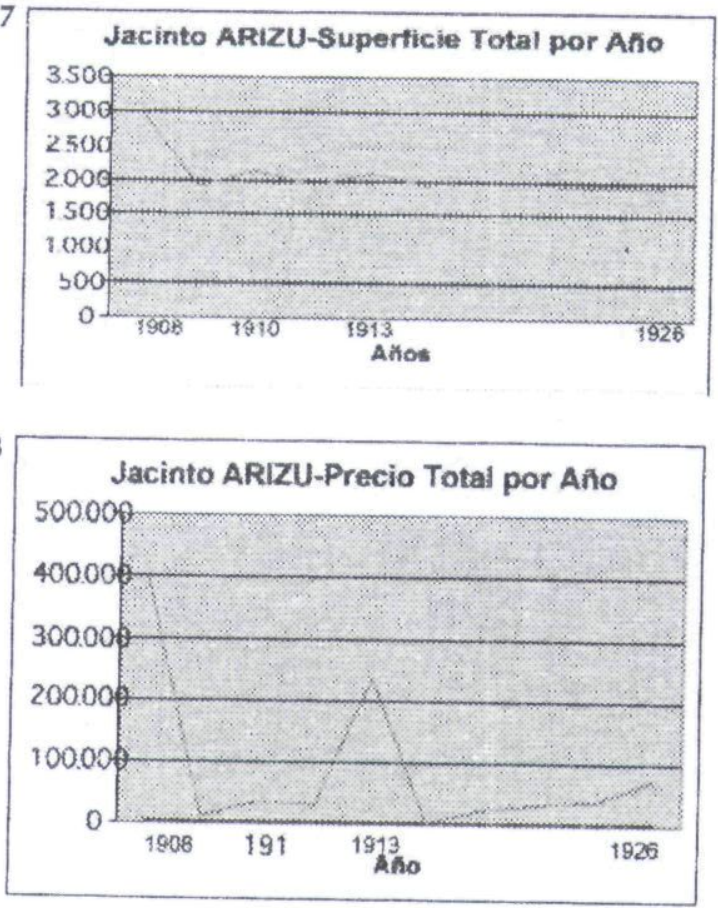
A lo largo del período analizado, Jacinto vendió 1.116 ha por un valor de $\$ 1.108 .364,96$.

\subsection{Sotero Arizu y sus descendientes}

La temprana muerte de Sotero truncó un futuro que comenzó como el más promisorio entre los hermanos. Entre 1908 y 1911 compró 3.040 ha en San Rafael y 340 en Luján, más otras operaciones que totalizaron 3.386 ha por un valor de \$ 1.080.308,50 (Gráficos 9 y 10). Los problemas por la sucesión descapitalizaron esta rama de la familia, que hacia 1920 había vendido 4217 ha.

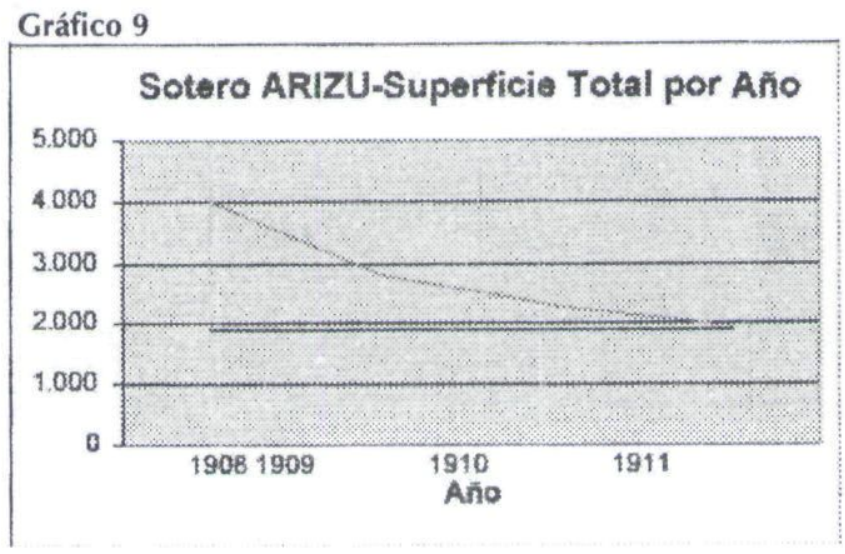

Gráfico 10

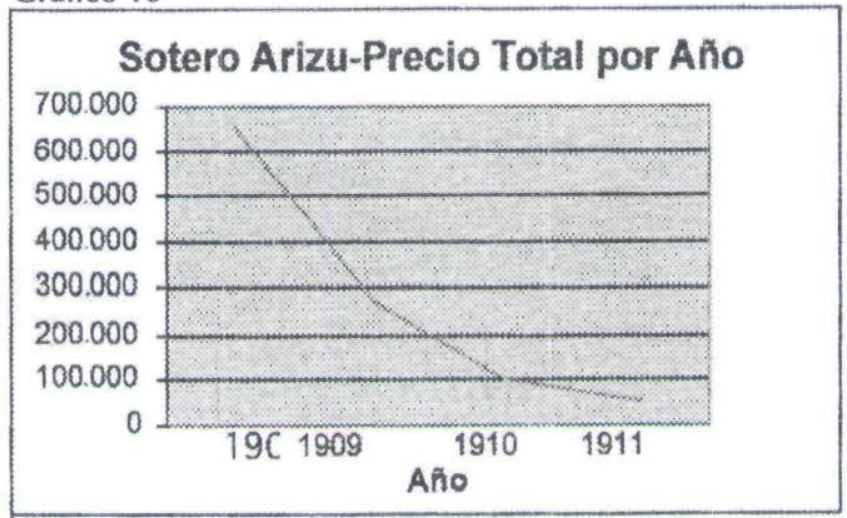




\subsection{Leoncio Arizu}

El sobrino que Balbino trajera desde España a los 7 años y que ya los 25 se desempeñaba como Gerente de la empresa, hizo un proceso mucho más lento de acumulación de tierras en el periodo. Solamente compró 317 ha repartidas en distintas zonas vitivinícolas, por un valor de $\$ 1.338 .103$ (Gráficos № 11 y 12). Su mayor inversión fue en Maipú, en Roussel. Solamente vendió media hectárea en el periodo.

Sin embargo, anticipando la carrera propia que muy pronto emprendería, fue el único que se animó a comprar una bodega a título personal en Luján. El resto de los familiares se limitaron a adquirir viñedos, cuyos frutos elaboraron en las bodegas de Godoy Cruz y de Villa Atuel, propiedad de la S.A. En 1922 se retiró de la firma y emprendió por cuenta propia una empresa de prestigio, cuyos nietos la han mantenido hasta la actualidad.

\section{Gráfico 11}

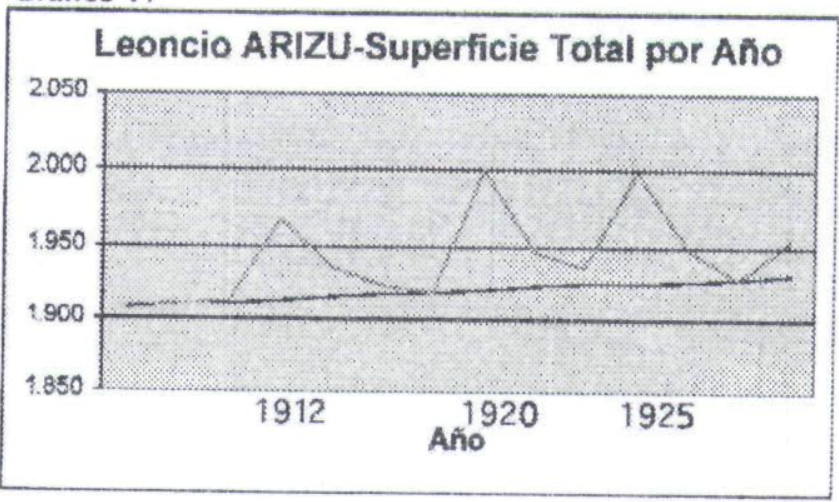

\section{Gráfico 12}

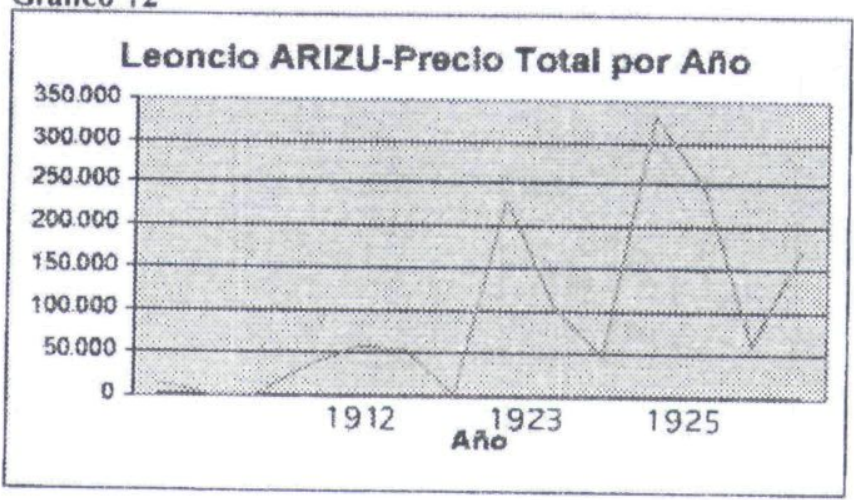




\section{Conclusiones}

El estudio precedente sobre las inversiones en viñedos de los Arizu nos muestra un sostenido crecimiento y una clara planificación estratégica. Se puede observar que a pesar de que las mayores inversiones se produjeron hacia la zona de Luján y Maipú (zona núcleo de la vitivinicultura), el mayor porcentaje de compras se realizó hacia San Rafael, en el sur mendocino, donde se constituyó "Villa Atuel", un verdadero poblado vitivinícola. Las mayores extensiones se adquirieron en Luján (9.351 ha) y en Maipú (2.029 ha), pero el mayor volumen de compras, a través de 60 operaciones, fue en San Rafael donde se acumularon 15.666 ha.

La mayoría de las operaciones fueron al contado. Sobre un total de 172 transacciones inmobiliarias, únicamente 14 fueron con garantía hipotecaria. Los intereses oscilaban entre 6 y $8 \%$ anual, los usuales en la época, a un plazo que generalmente no pasaba de los tres años. Es llamativo que cuando las compras y las ventas se hacían entre los hermanos no se cobraban intereses, pero sí se utilizaba la garantía hipotecaria.

La explicación para la expansión hacia el sur mendocino se sustenta en por lo menos dos razones. En primer lugar, el bajo precio relativo de las tierras del sur en comparación con los de la primera zona vitivinícola. El siguiente ejemplo es lo suficientemente elocuente: mientras que en 1906 una ha en Luján fue comprada en \$742 y a \$2.198 en 1908 en Maipú, el precio en las dos fechas en San Rafael fue de $\$ 100$ por ha. La segunda razón se relaciona con la factibilidad de dotar a los viñedos de agua de riego, posibilidad más difícil de concretar sobre el río Mendoza dada la gran expansión de los cultivos. Mientras solamente 45 ha de las fincas tenían riego definitivo sobre el río Mendoza, la mayoría de las tierras en el sur tenían derechos eventuales o definitivos.

El período empresarial y familiar analizado nos muestra el protagonismo de Balbino, el fundador y mayor tenedor de acciones, quien tempranamente desarrolló estrategias para conseguir su meta de "hacer la América", pero "en familia". Sin duda el puntapié inicial fue para él una correcta elección matrimonial: una viuda con dinero. La temprana desaparición de Sotero facilitó este paternalismo empresarial y familiar.

Balbino se comportó como una especie de dios que movió los hilos de la empresa hasta su muerte. La propia S.A. se manejó con criterios propios de una empresa familiar, a pesar del aporte de capitales ajenos. Solamente las presiones de la pesada deuda contraída con el Banco Nación y tal vez algunas dificultades en la relación política con personajes que ya habían dejado de brillar ${ }^{36}$, motivaron un temporario alejamiento de Balbino de su conducción.

Hubieron entre 1908 y 1920 algunos intentos por pasar a convertirse en

36 Emilio Civit deja la gobernación en 1909 y los gobernadores que lo suceden toman distancia de sus prácticas de gobierno. En 1918 asume el radical josé Néstor Lencinas. 
una "empresa moderna" según el paradigma de Chandler. Indice de esta búsqueda de cambios fue el nombramiento de un gerente ajeno al grupo, aunque duró un año en sus funciones, retornando esta función a un miembro de la familia. La contratación de la empresa Price and Waterhouse constituyó otra señal por adoptar parámetros más modernos.

La larga vida de Balbino, quien no tuvo hijos y la temprana muerte de Sotero, fueron factores que contribuyeron a la cohesión del grupo. Sin duda, la coincidencia entre "proyectos familiares" y "empresa" llevó a la potenciación de valores compartidos como el grado de compromiso y la confianza, aunque esta sinergia reposaba casi exclusivamente sobre la persona de la cabeza del grupo, lo cual demuestra, al mismo tiempo, las fortalezas y debilidades propias de las empresas familiares. Seguramente, la decisión de traer de España a un sobrino segundo para entrenarlo desde muy jóven tuvo que ver con la necesidad de ir preparando a un sucesor. Sin embargo, Leoncio se abrió de la firma para diseñar su propio proyecto.

No queremos dejar de mencionar el papel de las mujeres de la familia en el mundo de los negocios. De las tres mujeres del grupo de hermanos inicial, dos fueron monjas y quedaron en España. La otra, Eusebia, casó con Florencio Garde (quien se incorporó a la empresa) y tuvo una participación escasa, mediada por su rol de mujer y por el protagonismo de Balbino. Fue la proveedora del mundo de los afectos de su hermano, quien en su viudez se aferró a ella y a sus hijos.

La bodega de Godoy Cruz, de la que hemos extraído el material de archivo, funcionó como "empresa madre" y partir de ese "único escritorio" se manejaron la S.A y gran parte de los bienes personales de los hermanos. Cuando se fundó la bodega de Atuel, aunque fue administrada desde alli, las decisiones se tomaban desde Godoy Cruz.

Por último, creemos que a través de este estudio estamos en los inicios de caracterización de las estrategias de un empresario vitivinícola exitoso en los albores del siglo XX en Mendoza. En Balbino Arizu se superpusieron el capitalista, el gerente, el comerciante y el patriarca. Con mano firme condujo durante casi 50 años las actividades familiares y empresariales, pero lo hizo apoyado en un entrecruzamiento de lealtades que nacieron en España, se consolidaron en Mendoza, se abrieron hacia los circuitos comerciales del país y se reforzaron con vínculos políticos con personajes de la talla de Tiburcio Benegas y Emilio Civit y su círculo. Evidentemente estas redes sociales contribuyeron para que este grupo familiar y empresarial concretara el viejo mito de que cualquier inmigrante esforzado podía convertirse en millonario en la Mendoza en crecimiento de la época. Y también sirve para explicarnos porqué solamente para unos pocos se hizo realidad.

Recibido 04/07/02

Evaluado 23/11/02 


\section{Resumen}

Aproximación a la empresa Arizu: Algunas estrategias de la conformación e incremento del patrimonio societario y familiar 1884-1920

El estudio de la familia Arizu y de su actividad empresarial tiene por objetivo analizar las estrategias desplegadas para la conformación, en la Mendoza de principios de siglo, de un volumen de viñedos tan importante que llegó a ser conocido como "el paño de viñas más grandes del mundo". Para esta investigación hemos tomado como unidades de análisis a los individuos, la familia y las redes extraparentales y comerciales a partir del análisis de la información de las fuentes empresariales y de los protocolos notariales desde 1884, año de la llegada del primer miembro de la familia, hasta 1920.

Creemos que la importancia de este estudio reside en que la escala microhistórica del enfoque nos brinda un nuevo marco para análisis más amplios sobre la economía vitivinícola y nos permite validar o reformular algunas de las versiones sobre el proceso de conformación de la alta burguesía vitivinícola y el papel en ella desempeñado por los inmigrantes. Por otra parte, nos permite conocer las estrategias que posibilitaron que los Arizu se ubicaran en período analizado en el tercer lugar dentro de los productores mendocinos. Y por último nos acerca al conocimiento de la estructuración y el funcionamiento de las redes familiares, de paisanaje y clientelares como posibilitadoras y facilitadoras del éxito económico.

Palabras claves: Vitivinicultura-empresa-redes sociales-burguesía vitivinícola

\section{Summary}

An approach to Arizu's enterprise: some strategies to make and increase the social and familiar patrimony. 1884-1920.

This study of Arizu's family and their enterprise's activity, examines the strategies for the purchase of an important volume of vineyards. These were known as "the largest carpet of vineyards of the world" in Mendoza at the begining of the twentieth century. For this research we have taken the persons, the family and the social networks as units of analysis, resorting to the information of the books of the Arizu enterprise and to the notary's registers since 1884, year of the arrival of the first member of the family, up to 1920.

We believe that the importance of this study is the microhistory perspective that offers a new point of view of the winegrowing economy. It also allows us to validate or discuss some of the versions concerning the shaping of the high winegrowing bourgeoisie and the role of immigrants. Appart from this, it lets us know the strategies that made it possible for the Arizu's to be in the third place of the provincial producers. Finally, this study gives us information about the relationship between social networks and economic success.

Key words: Viticulture -business history -social networks - economic power 


\section{Documentación}

MENDOZA, Protocolos Notariales. AHM.1880-1930.

MENDOZA,Síntesis de los Anuarios de la Dirección General Estadística 19161922, Peuser, Buenos Aires, 1923.

ARGENTINA, Tercer Censo Nacional. Rosso y Cia, Buenos Aires, 1914. 8 tomos. MENDOZA, Páginas Argentinas.La Provincia de Mendoza durante el gobierno de C.W. Lencinas, Buenos Aires, 1924.

CENTRO VITIVINICOLA NACIONAL, La vitivinicultura en 1910, Buenos Aires, s/f. BODEGA ARIZU, Libros de la empresa. 1897-1930.

\section{Referencias Bibliográficas:}

BALAN, Jorge y Nancy LOPEZ (1977)"Burguesías y gobiernos provinciales en la Argentina. La política impositiva de Tucumán y Mendoza entre 1874 y 1914”, en Desarrollo Económico $N^{\circ}$ 67. Buenos Aires, IDES:391-435.

BALAN, Jorge. (1978) "Una cuestión regional: Burguesías provinciales y el mercado nacional en el desarrollo agroexportador", en Desarrollo Económico, $N^{\circ} 69$, Buenos Aires, IDES:49-87.

BARBERO, María Inés (1993) Historia de Empresas. Buenos Aires, CEAL.

BRAGONI, Beatriz (1999) "Meritorios españoles, ejemplares noblres". Inmigración, redes y mercado: Algunas notas sobre la formación de emporios vitivinícolas en Mendoza, 1860-1940", en FERNANDEZ, Alejandro y MOYA, José (edit).La inmigración española en la Argentina. Buenos Aires, Biblos:115-140. BJERG, María y OTERO Hernán (1995) (comp.) Inmigración y redes sociales en Argentina moderna, Tandil, CEMLA-IHES.

CARDOZO, Ciro y PEREZ BRIGNOLI, Héctor (1984) Historia económica de América Latina, T. II. Economía de exportación y desarrollo capitalista.Crítica, Barcelona

CLEMENTI, Hebe (1991) (coord) Inmigración española en la Argentina, Oficina Cultural de la Embajada de España, Buenos Aires.

CORTES CONDE, Roberto (1979) El progreso argentino. 1810 1914. Buenos Aires.

DEVOTO, Fernando J. (1994) Movimientos migratorios: historiografía y problemas, Buenos Aires, Centro Editor de América Latina.

DIAZ ALEJANDRO, Carlos (1975) Ensayos sobre la historia económica argentina, Buenos Aires, Amorrortu.

DORFMAN, Alejandro (1970) Historia de la industria argentina. Buenos Aires, Solar-Hachette.

FLORESCANO, Enrique (comp) (1984) Orígenes y desarrollo de la burguesía en América Latina (1700-1955), Buenos Aires, Nueva Imagen.

FRID de SILVERSTEIN, Carina (1995) "De la red al mercado: procesos de 
especialización profesional de tres estudios de caso (Rosario, 1890-1930)" en BJERG, María y OTERO, H. (comp.) Inmigración y redes sociales en Argentina Moderna, Tandil, CEMLA-IHES.

GIRBAL DE BLACHA, Noemí (1982) Historia de la agricultura argentina a fines del siglo XIX. Buenos Aires, FECIC.

GIRBAL de BLACHA, Noemí (1988) "Estado, modernización azucarera y comportamiento empresario en la Argentina, 1876-1914: expansión y concentración de una economía regional", en Anuario de Estudios Americanos, XLV, Sevilla: 383-417.

MARTIN, Francisco (1992) Estado y empresas. Relaciones inestables. Políticas estatales y conformación de una burguesía industrial regional. Mendoza, EDIUNC.

MATEU, Ana María y GASCON, M. (1990) "El surgimiento de la burguesía vitivinícola en la provincia de Mendoza. Argentina a finales del siglo XIX", en Revista Paraguaya de Sociología $\mathrm{N}^{\circ} 77:$ 117-140.

MATEU, Ana María (1994) "Bancos, créditos y desarrollo vitivinícola", en Cuadernos de Historia Regional, Universidad Nacional de Luján, N.17: 133-162. MATEU, Ana María (1996) "Estado y vitivinicultura. Las políticas públicas de la transición. Mendoza. 1870-1890", en Actas de las Jornadas sobre Elites, cuestión regional y Estado Nacional. Tucumán. (En prensa).

MATEU, Ana María (1998) "La Bodega Arizu (Mendoza, Argentina) y su incorporación al mercado interno argentino", en Jornadas Internacionales de Historia Económica, Madrid.

MATEU, Ana María (2002) "Los caminos de construcción del cooperativismo vitivinícola en Mendoza, Argentina (1900-2000)", en CD Jornadas de Historia Económica Internacional, Buenos Aires.

RICHARD, Rodolfo (1994) "Estado y empresarios regionales en los cambios económicos y espaciales :la modernización de Mendoza 1870 y 1910", en Siglo XXI-Cuadernos de Historia, $\mathrm{N}^{\circ}$ 9, Instituto Mora Monterrey, Méjico: 69-99. 